\title{
ASPEKTE VAN DIE SIEKEPASTORAAT
}

\author{
Dr. H. J.C. Pieterse
}

\section{INLEIDING}

Die siekepastoraat vra ons aandag in hierdie tyd omdat die versorging van siekes ' $n$ kenmerk is van die koms van die koninkryk van God. God se barmhartigheid het in sy volheid tot gelding gekom in die optrede van Jesus Christus. Die volle seën van die heil van die Ryk van God hou ook die versorging van die siekes in. Deur die heilswerk van Christus sien die blindes weer, loop die kreupeles, word melaatses gereinig, hoor die dowes, word dooies opgewek (Luk. $7: 22$ ).

Voorts is die siekepastoraat opgedra aan die gemeente van die Here. Christus sit Sy dienswerk voort in en deur Sy gemeente. Deur die hande, voete, oë, ore en mond van die besondere en algemene ampte sit Christus Sy dienswerk voort. Daarom moet die gemeente namens Hom en as Sy orgaan die siekes versorg (Matt. $25: 36,40$; Jak. $5: 14$ ).

Temeer is hierdie saak in ons tyd aktueel vanweë die verandering in houding by die Westerse mens teenoor siekte en dood. Die welvarende, materialisties gerigte en tegnies gevorderde Westerling ignoreer dood en lyding as 'n taboe. Lydendes en sterwendes word uit die huise en maatskanpy verwyder, in hospitale en inrigtings gebêre en wanneer hul sterf so onopsigtelik moontlik en gladweg weggelê. Ten spyte van hierdie wegvlug van lyding en dood, en miskien júis daarom, is die vrees vir lyding en dood eens so erg. Lyding het sy sin en betekenis vir baie verloor omdat die perspektief op die ewige verlore gegaan het. Juis in hierdie situasie moet die herderlike sorg toegespitste aandag aan die siekes gee om hulle tot sinvolle belewenis van siekte en dood te lei.

Siekepastoraat is 'n onderdeel van die herderlike sorg. Herderlike sorg is gesnreksmatige Woordbediening aan die mens in sy situasie. Dit is Woordbediening langs die weg van begeleiding. Die Woord van God funksioneer in hierdie gesprekmatige begeleiding nie as antwoorde wat kitsklaar vir elke situasie uitgedeel word nie, maar moet in die pastorale verhouding as gebeure ervaar word. Pastor en gemeentelid moet saam in die nood van die situasie die Woord van God hoor wat die lig in die nood bring. Die pastorale begeleiding help die gemeentelid om in die regte verhouding tot God te staan te kom en so meteen met sy medemens en omliggende wêreld. Die herderlike sorg mond uit in allerlei toespitsinge: die pastoraat aan die bejaarde, alkoholis, treurendes, die krisispastoraat, huwelikspastoraat en siekepastoraat. In die toegespitste siekepastoraat sal dit uiteen val in die pastoraat aan die sieke, die terminale pasiënt en die psigiatriese pasiënt.

Die siekepastoraat bied groot geleentheid vir die bediening van die versoening omdat die gemeentelid uit die besige lewe onttrek 
word en tot groter besinning oor die sin van die lewe kom. Dit bied ' $n$ openheid en ontvanklikheid vir die Woord van God en lei tot 'n inniger verbondenheid met die gemeente. Hierdie geleentheid moet deur die kerk benut word.

Dit is onmoontlik om hier enigsins volledig op hierdie saak in te gaan. Daarom behandel ons heel oorsigtelik sekere aspekte van die siekepastoraat met groter klem op drie sake, nl. die euthanasie, die verpleegster en die hospitaalpredikant. Ons sal dus eerstens let op enkele uitgangspunte t.o.v. ons benadering tot hierdie saak, nl. die doel van siekepastoraat, dogmaties-etiese vraagstukke waaronder die euthanasie, insig in die psigiese en fisieke gesteldheid van die sieke en die noodsaak van trouheid deur die pastor aan sy rol. Verder word die sieke tuis en die sieke in die hospitaal bespreek, waarby die dienswerk van die verpleegster en die pastoraat in mediese konteks meer in besonderhede behandel sal word.

\section{UITGANGSPUNTE}

\subsection{Die doel van siekepastoraat}

Die doel van siekepastoraat, soos met alle pastoraat, is om die Woord van God aan die mens in sy situasie te bedien. Die Woord moet in al sy ryke skakeringe van kerugma, paraklese en didache bedien word. Die Woord moet die totale bestaan van die mens tref en hom in sy hele mensheid aanspreek en tot heelheid in Christus bring. Die mens wat onderworpe is aan siekte is ook onderworpe aan sonde. Soos die hele mens sondig is, is ook die hele mens siek. Die mens is 'n psigo-somatiese wese. Daarom sal die Woord nie net perspektiewe open i.v.m. die ,siel" nie, maar ook t.o.v. die liggaam, dus: die mens in sy totaliteit.

Die Woord moet tot die sieke in sy situasie kom. Daarom moet die behoefte wat op 'n gegewe moment op die bewussynsdrumpel van die sieke lê deur luister en deur navraag vasgestel word. $\mathrm{Na}$ hierdie behoefte moet daar opgetree en gelei word. Die behoefte van die dag, hoe ,aards" dit ook vir die pastor klink, moet ernstig geneem word en die Woord moet na die behoefte bedien word.

Saam met die Woordbediening gaan die gebed. Die gebed mag nie gemanipuleer word tot 'n terapeutiese middel of 'n magiese en sensasionele wonderwerker nie. Dit is die intrede by God vir die sieke, die voordra van die node, die smart en die dank van die sieke voor die troon van God. By die aftakeling van die liggaam word die psigiese $\mathrm{krag}$ só laag dat iemand anders die gevoelens van die sieke aan God moet oordra. Soms is die sieke so swak, verward en geskok dat hy nie self sy behoefte in woorde kan stel nie. Terwyl daar om die genade en genesing van God gepleit word, moet dit steeds gebed wees wat in Gods soewereine wil berus.

Die doel van siekepastoraat is dus om die Woord en die gebede in die situasie van die sieke te bedien sodat hy tot ware geloof en verwerking van sy siekte gelei word. Ten diepste is die doel hiervan die verwerkliking van die koninkryk van God in die lewe 
van die sieke. Wanneer die Koninkryk in sy volheid in sy lewe deurbreek, kom hy tot homself en word die koninkryk van God as die kernbegrip van die lewe van die gelowige aangegryp (Matt. $6: 33$ ). Slegs langs hierdie weg kan hy in die regte verhouding tot God, homself, sy siekte, sy medemens en die omringende wêreld kom.

So word hy gelei tot verwerking van sy siekte en insig in die sin van sy lyding, nl. as toetsing, beproewing, tugtiging, koppeling aan Christus alleen, versterking van die gemeenskap van die heiliges en uitsig op die ewige lewe. Dit alles kán vanuit die oorwinning deur die opstanding van Christus.

\subsection{Dogmaties-etiese vraagstukke}

Die pastor wat die sieke versorg, sal hom deeglik van die dogmaties-etiese vraagstukke wat in hierdie veld na vore tree moet vergewis. Hy sal die visie van die Skrif op die betrokke veld helder moet hê en dit in sy pastoraat op die regte wyse moet kan oordra.

Die eerste vraag is: wat is siekte? Die Skrif wys op die noue verband tussen sonde en siekte. Dit is egter geen direkte band in kousale sin nie (Job 42:7; Joh. 9:1). Maar die mens wat in 'n toestand van sonde is, is ook daardeur dodelik krank. Die sonde het die verhoudinge met God, die self, die medemens en die omliggende wêreld (ook die natuur) geskend. Die Bybel sien die mens as prinsipieel 'n kranke wat siek is tot die dood. Hierdie aftakeling en dreiging hang steeds oor hom. Die liggaamlike siekwees wys heen na 'n meer eksistensiële siekte, nl. die siekwees voor God en teenoor God. Siekte is dus on-natuurlik, 'n onorde, 'n wan-orde.

$\mathrm{Na}$ die oorsprong van die lyding word dringend deur die sieke gevra. Die teologie mag nooit die kwaad en God met mekaar probeer versoen of uitredeneer nie. God mag nooit geregverdig word deur 'n teodisee nie. Die oorsprong van die kwaad en lyding bly 'n raaisel, 'n misterie. Eén ding weet ons: dat God Hom inlaat met ons en dat Hy nogtans, ten spyte van die lyding Sy liefde in Christus aan ons betoon (Kom. $5: 8$ ).

Gesondheid is nie slegs die goeie funksionering van die liggaam nie. Die mens het nie net ' $n$ bestaan nie, maar 'n bestemming. Die ware gesondheid moet op die bestemming gerig wees. Werklike gesondheid is dus geleë in die krag om mens te wees in die lig van Gods genade, die krag om God te dien. Deur Christus se heilswerk kan die versteurde verhoudinge weer herstel word. Ware gesondheid is dus die lewe in die regte verhoudinge tot God, die self, die medemens en die omliggende wêreld. Selfs onder liggaamlike lyding en siekte kan die mens sy ware menssyn uitleef en "gesond" wees. Dit open perspektiewe vir die siekepastoraat, nl. dat mense in 'n chroniese siektetoestand gelei kan word tot ware menswees en tot 'n doksologie.

Met gebed, geloof en genesing moet sober omgegaan word. Die gebed by die sieke word beveel en die gebed van die gelowige het groot krag. Maar die genesing is 'n gawe van God en berus in Sy 
soewereine wil. Daarom is geloof en gebed nooit grond vir genesing nie, maar die onuitspreeklike genade van God. Die diens van die gebede behoort dus nie in die raamwerk van die demonstratiewe nie, maar in die alledaagse pastorale konteks te geskied. Die genesing hang nie af van 'n ,geloofsgeneser" nie, maar van die wil en die vrye genade van God.

Rondom die eutanasie (genadedood) het 'n heftige diskussie in die laaste jare ontstaan. Die diskussie het egter ook ander sake aangeraak soos die kunsmatige verlenging van die lewe, die vraag oor wanneer 'n mens werklik dood is en orgaanoorplantings. Ons let hier veral op die eutanasie en die kunsmatige verlenging van die lewe.

Die vraag oor die ingryping deur medici op die lewe en dood het ontstaan a g.v. die mediese mag wat voortvloei uit die gevorderde tegniese en wetenskaplike vermoëns van die medikus. Ons onderskei tussen passiewe en aktiewe eutanasie. Aktiewe eutanasie is die aktiewe eiemagtige ingryping van die een mens in die lewe van 'n ander. Die outonome mens loer hier om die hoek-dié mens wat glo dat hy nie net oor sy eie lewe mag beskik nie, maar ook oor dié van 'n ander waarvoor hy verantwoordelikheid het. Dit sou dan eties-godsdienstig geregverdig wees om uit medelye, op versoek van die sieke of van die familie in geval van ongeneeslike siektes, erg verminktes of seniele bejaardes die einde te bewerkstellig deur die toediening van sekere middele. Passiewe eutanasie is die staking van behandeling by gevalle soos hierbo vermeld en die gevolglike beëindiging van die lewe.

Argumente ten gunste van eutanasie is o.a.:

$\star$ Die sinvolheid van die lewe. Dit is slegs nodig om die lewe te behou waar die lewe sinvol is. Waar ' $n$ mens geen mens meer is nie, is dit sinloos om sy lewe aan die gang te hou. Die menselewe het dan 'n minimale betekenis en 'n maksimale lyding te verduur.

* Die gevaar vir die gemeenskap. Daar kan gevalle wees waar die waarde van die mens se lewe minder as nul is, bv. by ongeneeslike aansteeklike siektes wat 'n werklike gevaar vir die gemeenskap inhou.

$\star$ Die vryheid van elke mens om self te kies of hy wil sterf of nie.

* Die nuttigheidspotensiaal van 'n mens wat oud of terminaal siek of erg vermink is. Vir homself en die gemeenskap beteken hy nie meer iets nie en hy is net 'n bron van smart vir almal wat met hom te doen het.

Argumente teen die eutanasie is o.a.:

$\star \quad$ Die mens kan nie beskik oor die beoordeling van die sinvolheid of onsinvolheid van die lewe nie. As die lewe van iemand beëindig moet word wanneer dit deur homself of deur iemand anders nie meer as sinvol beskou word nie, is die weg oop na selfmoord en moord. God bepaal die tydsduur en die sin van die lewe. 
* As nie alle lewe nie, maar alleen die gesonde lewe as sinvol en tot die beswil van die gemeenskap beskou word, word gesondheid as die hoogste waarde beskou waaraan alle ander opgeoffer word. Dit is 'n biologisering van die menslike lewe en is wesenlik onmenslik. Daarom sal dit lei tot 'n sg. "gesonde" gemeenskap wat egter on-menslik is.

* Nie die mens is vry om oor sy lewe te beskik, maar God beskik oor lewe en dood en oor die lewe van elke mens.

* Bruikbaarheid is nie die maatstaf vir menslike lewe nie, maar die mens het as mens oneindige waarde omdat hy beelddraer van God is en deur Hom as kosbaar beskou word. Die lewe wat God geskep het en in stand hou het 'n inherente waarde wat volkome onafhanklik is van menslike beoordeling. Daarom het 'n oënskynlik nuttelose en selfs pynvolle lewe 'n funksie in die wil en raad van God - God het 'n doel met so 'n mens.

Die kunsmatige verlenging van die lewe ten alle koste vanweë die mediese mag is ' $n$ probleem wat van die eutanasie onderskei behoort te word. Hier ontstaan vrae soos: op welke moment tree die doodsmoment in? Wat is die kriterium vir die doodsmoment? Welke definisie van dood en lewe is die korrekte? Is dit die mediese roeping om die biologiese lewe op kunsmatige wyse vir 'n tyd te verleng? Twee sake kom hier skerp na vore. Deur die lewe kunsmatig aan die gang te hou kan die beskikking oor lewe en dood deur God ook uit Sý hand geneem word deur die doodsmoment te oorskry. En verder behoort die mens die geleentheid gegun te word om sy eie dood te sterf, d.w.s. op 'n natuurlike wyse. Dikwels is dit op aandrang van die familie dat 'n pasiënt op kunsmatige wyse langer aan die gang gehou word. Hierin lê ook 'n ontmensliking deurdat die moontlikheid om waardig te sterwe hom ontneem word.

Konkluderend sou ons so kon formuleer: God beskik oor lewe en dood. Ons tye is in Sy hand. Net Hy het die reg op ons lewe en ons sterwe. Geen mens mag dus ingryp om oor lewe of dood te beslis nie. Daarom sal die lewe nóg voor-tydig ontneem mag word, nóg na-tydig kunsmatig verleng mag word. In elke geval sal almal wat betrokke is - die pastor, die mediese personeel, die familie en die pasiënt die wil van God moet soek.

\subsection{Trou aan die rol van die pastor}

'n Verdere uitgangspunt is dat die pastor in sy siekepastoraat trou aan sy rol as pastor sal wees. Hy is en bly een en al bedienaar van die Woord. Dat hy van die insigte van die buurdissiplines of hulpwetenskappe soos die sielkunde, die sosiologie, die toegepaste sosiologie, die psigiatrie e.a. moet gebruik maak, spreek vanself. $\mathrm{Hy}$ is egter geen kwasi-medikus, geen kwasi-psigoterapeut nie. Hy is Woordbedienaar. Die herderlike sorg mag ook nie aan die psigoterapie gelyk gestel word nie. Die psigoterapeut het sy eie legitieme terrein.

Hoewel baie pastores in 'n rolkrisis verval, veral as hulle toegespitste werk begin verrig, soos bv. die hospitaalpastoraat, is die 
gemeente nie onduidelik in hul rolverwagting van die pastor nie. Hulle verwag van hom dat hy mét hulle sal wees, dat hy na hulle sal luister, dat hy hulle sal begryp en hul nód sal begryp, dat hulle van hom en saam met hom die Woord van Gód sal hoor, wat lig bring, wat 'n uitweg uit die nood aanwys, wat hulle tot sinvolle aanvaarding en verwerking van hul nood sal bring. Kortom, hulle verwag van hom God se Woord.

Selfs die kleredrag van die pastor is belangrik t.o.v. die gemeente se rolverwagting. Die pasiënt wat bv. in die hospitaal lê se daaglikse roetine word heeltemal volgens rolfunksionering ingerig. As die dokter inkom met sy witjas of -baadjie, verwag hy dat die dokter iets aan sy kwaal sal doen. As die verpleegster inkom met haar kenmerkende kleredrag verwag hy versorging. As die fisioterapeut inkom met haar kenmerkende kleredrag verwag hy die nodige oefeninge. As die pastor inkom wil hy nie nóg 'n witbaadjie sien nie dit skep 'n verwagtingsverwarring - maar verwag hy Woordbediening in sy situasie. Daarom moet die pastor sekuriteit aan die gemeentelid gee - ook met sy kleredrag - wat gekoppel is aan sy herinnering uit die gemeentesituasie.

\subsection{Insig in die psigiese en fisieke gesteldheid van die sieke}

'n Laaste uitgangspunt is dat die pastor, as hy effektiewe siekepastoraat wil beoefen, nie totaal onwetend teenoor die fisieke en psigiese toestand wat elke soort siekte meebring, sal staan nie. Hy moet veral die verskynsels rondom elke soort siekte onderken en begryp. Eers dan kan hy die behoefte van die gemeentelid goed verstaan en die Woord effektief bedien.

Wanneer iemand siek word, word daar sekere emosionele konflikte geskep, bv. konflik met sigself, met die omgewing, met die eie liggaam en selfs met God. Gevoelsreaksies soos onsekerheid, eensaamheid, afhanklikheid, opstandigheid en twyfel kan na vore kom. Daar kan ook gevoelsverdediginge intree soos ontvlugting en rasionalisasie.

By die liggaamlik gestremde kan daar fases ontwikkel soos skok, ontkenning, onttrekking, erkenning en aanpassing. So het verskillende siektes elk op sy eie wyse 'n besliste invloed op die belewing van die siekwees. Die belewinge van die kankerpasiënt, hartpasiënt, teringlyer, nierpasiënt, die pasiënt met septiese infeksies, ens., verskil almal van mekaar. Daar is 'n psigo-somatiese wisselwerking tussen gevoelsbelewing en siektesoort.

\section{DIE SIEKE TUIS}

Die eerste vereiste is dat die gemeente opgeskerp moet word om van siekte kennis te gee aan die besondere ampte. Die ouderling, diaken en leraar moet ook onmiddellik mekaar in kennis stel as hulle van siekte hoor. Onmiddellike reaksie en besoek is baie belangrik.

'n Faset van die pastoraat aan die sieke tuis wat ons hier wil 
uitlig is die inskakeling van die gemeente in die pastoraat aan die sieke. Die sieke word geïsoleer van die gemeenskap en beleef sterk gevoelens van eensaamheid. Dit geld in 'n besondere mate van die chroniese sieke en die bejaarde wat siek is. Die gemeente is geroepe tot die koinonia met mekaar. Hulle moet op mekaar ag gee (Heb. 10:24), mekaar se laste dra (Gal. 6:2), mekaar aanvaar (Rom. $15: 7)$, mekaar van dwaalweë teruglei (Jak. $5: 19,20$ ), die onordelikes vermaan, die kleinmoediges bemoedig, die swakkes ondersteun ( 1 Thess. $5: 14$ ). In die kleingroep (die wyk) moet die warme medemenslikheid beleef word. So word in die gemeente die dinamiese terapeutiese kragte ook vir die sieke losgemaak. Dit het groot waarde by die ondersteuning, die hoop en die verwerking van die siekte. Die besondere ampte moet die leiding neem in die stimulering van die gemeente tot die besoek aan die sieke.

\section{DIE SIEKE IN DIE HOSPITAAL}

In die Angelsaksiese wêreld is die teenwoordigheid van 'n „chaplain" in die hospitaal sedert die vorige eeu al 'n praktyk. In ons tyd staan hul veelal los van die kerk en word hulle salarisse selfs uit sekulêre bronne (staat) verhaal. Ook in Suid-Afrika het die hosiptaalpredikant, of die leraar met toegespitste opdrag rondom hospitaalpastoraat, almeer inslag gekry.

4.1 Dit is nodig dat ons in die rigting van 'n roldefiniëring beweeg t.o.v. die plek van die plaaslike leraar en die hospitaalleraar wanneer 'n gemeentelid na die hospitaal gaan.

Alhoewel die hospitaalleraar toegespitste werk t.o.v. siekepastoraat verrig en dus ' $n$,spesialis" op die gebied is, moet ons in brginsel sê dat hy 'n aanvullende hulp vir die plaaslike leraar is. Die kudde is aan die ampte van die plaaslike gemeente opgedra. Dáár is hulle lidmate, dáár geniet hulle die voorregte van die sakramnnte. dáśr staan hulle onder die onsig en toesig van die kerkraad. Hulle is die verantwoordelikheid van die algemene en besondere ampte van die plaaslike gemeente.

Ons moet dus 'n kernbegrip in die raaknunte tussen plaaslike en hospitaalleraar formuleer, nl. noue skakeling en neinteoreerde samewerking. In hierdie skakeling kan die volgende uitgewerk word: (a) Indien ' $n$ gemeentelid van 'n verafgeleë gemeente in 'n stadshospitaal beland en die plaaslike leraar onmoontlik sy gemeentelid effektief kan besoek, kan hy die hospitaalleraar versoek om die pastoraat te behartig.

(b) Indien 'n gemeentelid van bv. 'n voorstedelike gemeente in die hospitaal opgeneem word en daar 'n noue band tussen hom/haar en die plaaslike leraar bestaan en die plaaslike leraar die pastoraat effektief kan behartig, behoort die hospitaalleraar terug te staan. (c) Indien die plaaslike leraar die hulp van die hospitaalleraar as opgeleide persoon vir die toegespitste pastoraat benodig, kan die hospitaalleraar ingeroep word.

(d) Indien die hospitaalleraar in die kontak met die hospitaalspan 
(medikus, verpleegster, psigiater/sielkundige, maatskaplike werkster) opgeroep word tot sý aandeel in die arbeid aan die sieke, kan sy dienste wat nodig is met die plaaslike leraar uitgespel word.

(e) Indien die hospitaalleraar intens betrokke is by die sieke kan die noodsaaklike sorg aan die familie met die plaaslike leraar bespreek word, wat natuurlik sy taak en verantwoordelikheid is.

4.2 Oor die posisie en taak van die hospitaalleraar moet verder besin word. Wat sy posisie betref, moet ons dit duidelik stel dat hy aan ' $n$ standplaas verbonde moet wees waar hy onder die opsig en toesig van die kerkraad arbei. Vanuit die gemeente waaraan hy verbonde is kan hy deeltyds afgesonder (as deel van sy gemeentelike taak omdat die hospitaal geografies in die gemeente ressorteer) of selfs voltyds afgesonder (omdat die hospitaal in die gemeentegrens ressorteer) by die hospitaal werk. Vanuit gereformeerde standpunt mag ons nooit toelaat dat die pastor los van die gemeente in die hospitaal optree riie. Die herderlike gesprek is 'n kerklike gesprek en moet die gemeentelid altyd benader in die konteks van die gemeente en die kerk. Dit beteken dat ook die hospitaalleraar trou aan sy rol as pastor moet bly soos in 2.3 aangetoon.

Wat sy taak aanbetref, is dit beslis 'n pastoraat in mediese konteks. Vanuit die gemeente staan hy in die mediese konteks. Daarom vorm hy deel van die span in die hospitaal wat die sieke versorg. Dit sluit die mediese dokter, die verpleegster, die psigiater/ sielkundige en die maatskaplike werkster in. In hierdie spanverband moet hy deel hê aan die besprekinge oor die nood van die pasiënte.

Dit is verder ' $n$ toegespitste pastoraat waarin hy die nodige kennis en onderlegdheid moet hê om effektief die Woord in daardie besondere situasie te bedien. Die hospitaalpastoraat stel die eis van intensiewe beraad. Om hierdie rede is hy beskikbaar as hulp vir die plaaslike leraar.

Voorts het hy 'n evangelisasietaak. Mense wat geen kerkverband het nie of vervreemde bondelinge is, moet bereik, gedien en weer terug in die gemeenskap van die heiliges geplaas word.

Daarom moet die hospitaalleraar die gemeente inspan in sy werk en van die algemene amp gebruik maak in die besoekwerk en diens aan die sieke. Ook die sieke in die hospitaal moet weet dat hy nie los van die gemeente kan staan nie.

Laastens het hy die taak om die hospitaalpersoneel te bedien omdat dit ' $n$ pastoraat in mediese konteks is. Hieronder tel die verpleegsters en paramediese studente in opleiding. Die geneeshere kan ook in beroepsverband bereik word.

\subsection{Die bediening aan en van die verpleegster.}

Naas die siekes behoort die hospitaalleraar ook 'n taak t.o.v. die personeel by die hospitaal te hê. In sy omgang met die span in die hospitaal het hy die geleentheid om die waarhede van die Woord oor te dra, bv. oor die eutanasie en ander etiese problema- 
tieke in die mediese wêreld, en is hy ook beskikbaar vir verdere gesprekke met die personeel.

$\mathrm{Hy}$ het veral 'n taak t.o.v. die verpleegsters wat dikwels in tehuise naby die hospitaal woon en dus ook geografies binne 'n gemeente ressorteer. By opleidingshospitale is daar groot getalle verpleegsters en paramediese studente in tehuise saamgetrek. Hy kan ook reëlings tref met ander gemeentes om verpleegsters in groepe toe te rus.

Die verpleegster speel ' $n$ baie belangrike rol in die hospitaal as versorgingspersoon, kontakpersoon en verwysingspersoon. Die gelowige verpleegster het 'n groot geleentheid om in haar werk in diens van Christus te staan. As gelowige staan sy in die amp en is sy geroepe tot die priesterlike bewoëndheid en versorging en het sy groot geleentheid tot die bring van die Woord en die gebed.

Die taak van die hospitaalleraar wat in mediese konteks sy pastoraat verrig t.o.v. die verpleegster sal dan eerstens wees om haar as gelowige op te bou en te versorg t.o.v. haar eie geloof. Die verpleegster sal begelei moet word in haar eie reaksie op die lyding waarmee sy gekonfronteer word. Dikwels reageer die verpleegster deur hard en onbetrokke te raak, of deur 'n geweldige emosionele krisis. Sy moet gelei word om Skriftuurlik die lyding te verstaan en te verwerk. Sy het behoefte aan leiding t.o.v. haar liefsdeslewe. Die kontak met die ontblote liggaam van die teenoorgestelde geslag kan lei tot allerlei konflikte en ongebalanseerde reaksies. Omdat verpleegsters dikwels groot eensaamheid beleef, moet hulle heg by die gemeente ingeskakel word. Hulle behoort as deel van die kerkjeug bedien te word.

Verder moet die verpleegsters toegerus word vir hulle dienswerk (Ef. 4:11-12). Die leer van die Skrif t.o.v. die problematieke in die mediese wêreld soos die eutanasie, kunsmatige verlenging van die lewe, aborsie, siekte, gesondheid, lyding, moet by haar tuisgebring word. Sy moet toegerus word om die siekes wat sy versorg ook te kan help rondom hul worsteling met God en hul geloof. Sy moet in staat wees as Christenverpleegster om diegene in nood te vertroos, te versterk en te lei uit die Woord van God.

\subsection{Die herderlike versorging van die sieke in die hospitaal.}

Ons het reeds daarop gewys dat elke soort siekte weer verskillende belewenisse en reaksies by die sieke ontlok. Ons het ook die rol van die plaaslike leraar en die hospitaalleraar probeer definieer. Hier wil ons net kortliks aandag gee aan die gewone siekte en die terminale siekte.

Dit is baie belangrik om te waak teen die gevaar dat te veel klem op die terminale siekte in die hospitaal gelê word en dat die gewone sieke dus nie genoeg aandag kry nie. Vandag se sieke wat vir ' $n$ klein operasie of ongesteldheid opgeneem word, kan môre se terminale sieke wees. Verder is dit so, dat elke siekte, en ten minste ' $n$ verblyf in die hospitaal, diep gryp in die lewe van elke mens. 
Wat die terminale sieke aanbetref wil ons wys op twee sake, nl. die fases wat dikwels in hierdie toestand deurgemaak word en die versorging van die familie.

Die lewendige debat en die stroom van literatuur oor die sterwensbegeleiding het in Europa nou heelwat in intensiteit afgeneem. Dit bly egter 'n saak wat steeds ons ernstige aandag verdien. In hierdie pastoraat word groot eise gestel en kom die wesenlike van die herderlike sorg na vore.

Dit is wetenskaplik vasgestel dat die meeste terminale siekes van hul toestand bewus word, selfs al is dit nie aan hul vertel nie. Dit is egter belangrik dat ' $n$ waarheidsklimaat in die herderlike begeleiding geskep word en dat niks weggehou word nie maar die realiteit in liefde oorgedra moet word aan die sieke en sy familie. Hierin kan die geneesheer ook van groot hulp wees. In die sterwensproses word gewoonlik vyf emosionele fases onderskei wat nie noodwendig kronologies hoef te verloop nie. By die gelowige hoef al die fases nie voor te kom nie, afhangende van die persoon en die kwaliteit van sy geloof.

(a) Ontkenning en isolering. Die toestand word ontken en die sieke sluit hom af van die ander.

(b) Opstand en woede. Dit is aggressie as uiting van hulpeloosheid. (c) Onderhandeling. As die Here hulle sou genees sal hulle 'n toegewyde lewe gaan voer.

(d) Neerslagtigheid (depressie). By die besef van die verlies van die lewe en die onvervulde ideale. Groot geloofstwyfel kan ook voorkom.

(e) Aanvaarding. Geloofsaanvaarding en 'n bereidheid om God te ontmoet.

Hierdie fases moet onderken word en die pastor moet die sieke begeleidend bystaan met die Woord van God.

Die familie van die terminale sieke het intensiewe sorg nodig. Dit is veral belangrik dat geleentheid geskep sal word vir die familielede om hul gevoelens te verwoord, die toestand te verwerk en die wil van God te aanvaar. Ook ná die dood ingetree het, moet die pastor sonder veel woorde mét hulle wees.

\section{SLOT}

Dat die siekepastoraat die ernstige aandag van elke pastor in ons tyd verdien, blyk duidelik. Die insigte van die hulpwetenskappe moet in ons pastoraat geīntegreer word. Dit kan slegs dien tot 'n effektiewer pastoraat aan die sieke in ons tyd. Onder alles moet die pastor Woordbedienaar bly en trou aan sy rol optree - ook in die hospitaal. Die heerlike ampsbediening ook aan die siekes is aan ons opgedra met 'n belofte daarby: „Hou as herders toesig oor die kudde van God wat onder julle is, nie uit dwang nie, maar gewilliglik; nie om vuil gewin nie, maar met bereidwilligheid; ook nie as heersers oor die erfdeel nie, maar as voorbeelde vir die kudde. En wanneer die Opperherder verskyn, sal julle die onverwelklike kroon van heerlikheid ontvang" (1 Petrus $5: 2-4$ ). 


\section{BIBLIOGRAFIE}

BAM, G., Die eiesoortige karakter van die pastorale sorg in die vorming van die volwasse persoonlikheid, D.Th.-proefskrif, Universiteit van Stellenbosch, 1966.

BERKELBACH VAN DER SPRENKEL, S. F. H. J., Huisbezoek, Amsterdam: Ploegsma, 1946.

BOOY, G. M., Pastoraat in die hospital, Proponentsverhandeling, Universiteit van Pretoria, s.j.

DE KI.ERK, J. J., Herderkunde, Pretoria: N.G.-Kerkboekhandel, 1978.

DE KLERK, W. J., Rousmart, Johannesburg: Boekhandel de Jong, 1972.

DE KLERK, W. J., Pastorale Sensitiwiteit, Johannesburg: Perskor, 1975.

DE VOS, W. A. K., Die herderlike sorg aan die vroulike hospitaalpersoneel met verwysing na die verpleegster en paramediese student in opleiding, B.D.verhandeling, Universiteit van Pretoria, 1978.

DREY ER, L., Hospitaalarbeid, in: Die Kerkbode, Jrg. 127, 24 Des. 1975.

EIBACH, U., Medizin und Menschenwürde. Ethische Probleme in der Medizin aus christlicher Sicht, Brockhaus, 1978.

FABER, H., De pastor in het moderne ziekenhuis, Assen: Van Gorcum, 1968

FABER, H., Is the Pastor a Psychotherapist?, in: The Journal of Pastorral Care, XXVII (1973).

FIRET, J., Het agogisch moment in het pastoraal optreden, Derde druk, Kampen: Kok, 1977.

FOSTER, L. M., The Chaplain: Patient's Advocate and Institution's Ombudsman, in: The Journal of Pastoral Care, XXIX (1975).

HEYNS, J. A., Die nuwe mens onderweg, Kaapstad: Tafelberg, 1970.

HILTNER, S., Fifty years of CPE, in: The Journal of Pastoral Care, XXIX (1975). JONKER, W. D., My tye is in U hand, in: Die Kerkbode, jrg. 127, 4 Junie 1975. KNIGHTS, W. A., Pastoral Care in Health Facilities-A book of Readings, St. Louis: The Catholic Association, 1977.

KUBLER-ROSS, E., On death and dying. London. New York. Toronto. Sydney. Wellington: Tavistock Publications, 1977.

LOUW, D. J., Voor-Sin-Igheid en die inlatende Wil van God; oor die probleem: God en Lyding, in: Ned. Geref. Teologiese Tydskrif XIX (1978).

MULLER, B. A., Die terapeutiese waarde van die gemeenskap van die heiliges in die pastorale sorg, in: Ned. Geref. Teologiese Tydskrif XI (1970).

NOLLE, F. A., Arts en predikant. Een beschouwing over grenzen en raaklijnen van hun beider arbeidsterrein, Utrecht: P. den Boer, 1952.

PIETERSE, H. J. C., Huwelikspastoraat, Pretoria: N.G. Kerkboekhandel, 1977. ROSCAM ABBING, P. J., Pastoraat aan Zieken, 's Gravenhage: Boekencentrum, 1964.

THIELICKE, H., The doctor as Judge of who shall live and who shall die, Philadelphia: Fortress Press, 1976.

VAN DEN BERG, J. H., Medische macht en medische ethiek, Sesde druk, Nijkerk: Callenbach, 1970.

VELEMA, W. H., Rondom het levenseinde, Kampen: Kok, 1971.

VENTER, C. J. H., By die sterfbed, Potchefstroom: Pro Rege, 1972.

WAHL, C. W., Helping the Dying Patient and his Family, in: Journal of Pastoral Care, XXVI (1972).

WIERSINGA, W. A., Op Ziekenbesoek, Amsterdam: Bakker, 1945. 
WOOLLEY, K. W., Care during terminal illness, in: The Journal of Pastorral Care, XXVI (1972).

WURTH, G. BRILLENBURG, Christelijke Zielszorg in het licht der moderne psychologie, Kampen: Kok, 1955.

WIJMANS, H., Pastor aan de rol. Over de rol van de pastor in de geestelijke gezondheidszorg, Nationaal Centrum voor Geestelijke Volksgezondheid, 1972. 